\title{
Evidences of investors' risk tolerance in Nairobi securities exchange: Does education or specialization matter?
}

\author{
Tobias Olweny a* \\ a Department of Finance and Accounting, Jomo Kenyatta University of Agriculture and Technology, Kenya \\ *Corresponding author’s email: toolweny@yahoo.com or tolweny@jkuat.ac.ke
}

H I G H L I G H T S:

1. The study tests the effect of education or specialization influence risk tolerance.

2. The sample of 500 investors includes investors trading at Nairobi Securities Exchange.

3. Result suggests that education level positively increases risk tolerance, while specialization reduces.

\begin{tabular}{|c|c|}
\hline Article History & A B S T R A C T \\
\hline $\begin{array}{l}\text { Received: 08-09-2014 } \\
\text { Revised received: 01-10-2014 } \\
\text { Accepted: 13-10-2014 } \\
\text { Available online: 24-10-2014 } \\
\text { Keywords: } \\
\text { Heuristics; } \\
\text { Logistic regression; } \\
\text { Risk tolerance; } \\
\text { Specialization. }\end{array}$ & $\begin{array}{l}\text { The main objective of the study is to evaluate the extent to which investors' education } \\
\text { level or specialization in finance or accounting determines investor risk tolerance at the } \\
\text { Nairobi Securities Exchange using a total of } 500 \text { individual investors out of } 9,32,510 \\
\text { investors holding CDS accounts. Data is collected through questionnaires comprising 13- } \\
\text { item risk tolerance instrument and demographic attributes that determine individual } \\
\text { investors' risk tolerance. Analytical framework included ordinal logistic regression model, } \\
\text { as well as an analysis of variance and Wolfowitz Wald test at } \alpha=0.05 \text {. The key findings are } \\
\text { that investor education level are significant in the determination of risk tolerance only at } \\
\text { below the high school level with a positive impact of } 1.831 \text { log of odd for every unit } \\
\text { increase in risk tolerance. Specialization in finance or accounting discipline also } \\
\text { influenced investor risk tolerance at a significance level of } 0.022 \text { with a negative impact of } \\
-0.389 \text {. }\end{array}$ \\
\hline
\end{tabular}

JEL Classification:

D14; D61; D91; G11.

DOI: http://dx.doi.org/10.18533/jefs.v2i05.145

(C) 2014 The Authors. This is an open access article under the terms of the Creative Commons Attribution License 4.0, which allows use, distribution and reproduction in any medium, provided the original work is properly cited.

\subsection{Introduction}

Investor risk tolerance is an important aspect in investment decision making. Rigorous theoretical analyses relating risk tolerance to optimal portfolios are based on the economic concept of risk aversion. The first trial at conceptualizing the investors risk aversion belongs to Friedman and Savage (1948), who explained investment behavior using the returns of risky financial investments behavior, and that of risky financial investments utility functions. They argued that the main factor that changes the investor's attitude towards risk is the size of their wealth. Further studies have shown that there are also other factors with direct impact over the attitude towards risk, which include economic growth forecast of a market, the level of training and experience gained, fluctuations of the exchange market and psychological factors among others. In an effort to understand the factors that influence the degree of risk aversion, Arrow and Pratt (1965), observed that investors with high risk aversion are less willing to take those risks, since the price for the given risk (risk premium) is much higher. In their approach, the main factors of risk aversion were the wealth of investors and the utility measure of the investors risk aversions. There are two major indicators that reflect an investors' risk tolerance: risk tolerance attitude and behavior; which are synthesized as above to develop utility function of the investor. Risk tolerance; a person's attitude towards taking risk, is a complex psychological concept. Jackson et al (1992), contend that risk tolerance has four dimensions: financial, physical, social and ethical. 
Irwin (1993) classifies the predisposing factors into two categories: environmental and bio-psychosocial factors. Environmental factors here include measurable individual and family financial attributes, such as income, net worth, and home ownership status. He defines bio-psychosocial factors to include characteristics such as age, gender, personality traits, birth order and ethnicity, which one has little or no control of. Other factors that appear to influence a person's financial risk tolerance include environmental factors such as financial knowledge, and family situation. Roszkowski (1999) and Sulloway (1997) contend that birth order is a significant factor influencing risk tolerance level of individuals. Haynes (2001) also found that factors such as age, race and net worth affect risk attitudes and behavior.

Friend and Blume (1975), estimated risk aversion by analyzing household portfolios and other decisions under risk. However, it is necessary here to assume that a household behaves with all information and rationality in order for such empirical analysis to reveal risk aversion. Risk tolerance can be operationalized as the inverse of relative risk aversion (Some researchers have proposed that risk tolerance is the inverse of risk aversion Brennan and Kraus (1976); Barsky, Juster, Kimball and Shappiro (1997). Grabble (2000), however they stated that financial risk tolerance is the maximum amount of uncertainty that someone is willing to accept, when making a financial decision. Risk tolerance is therefore an important concept that has implications for both financial services providers and consumers. Despite its importance in the financial services industry, there still remain some questions with respect to the 'determinants' of risk tolerance. The current theoretical review on risk tolerance and aversion determination is directed towards heuristics or rule of thumb. Investment decision making literature referring to heuristics defines the concept as a set of processes that assist with complex decision making and which are unproven, untested and may result in systematic biases. Shefrin (2001) defines heuristics as "rule of the thumb". Baker and Nosfinger (2002), in their review of behavioral finance, contend that heuristics are common investment decisions with cognitive and emotional biases leading to sub-optimal decision for investors

Many Kenyans rarely consult investment advisors licensed by the CMA whenever they intend to invest in the stock market (CMA, 2010). These advisors also tend to avoid provision of services to individual investors because of their low income level; they prefer dealing with institutional investors, who have regular income to pay advisory charges rather than erratic fee from individual investors. Brokerage firms and investment banks have played advisory roles to investors in Kenya from its independence to date (CMA, 2010). The advice however, is rarely objective because their principal aim is to convince the investors to open an account for their custody and earn commissions or brokerage fees. They seldom evaluate a person's investment policy for relevant decision making. In Kenya, individual investors are mainly guided by stock brokerage firms and investment bankers when selecting their optimal portfolio and setting their investment policy. The firms rarely evaluate formal factors influencing investor's risk tolerance and aversion level. As alluded to in the background of the study, the core competence of the firms is security trading rather than research and guidance on investor's portfolio management.

The paper reviews literature on the effect of education and specialization on risk tolerance from other countries to develop the hypotheses of study. Data is then collected and collated, relevant descriptive statistics are used to present the data. Ordinal Logistic Regression is applied as a model to determine the hypothesis and finally the findings are discussed for development of proposed policy implications.

\subsection{Literature review and hypotheses development}

Paun et al (2007), takes into account the demographic characteristics of Romanians, when estimating their risk aversion levels. Ajmi (2008), also applied a questionnaire on demographically segregated respondents in Bahrain, similarly Yuen and Chen (2008), employed a psychometric instrument to determine risk tolerance level in Hong Kong. Education is thought to increase a person's capacity to evaluate risks inherent to the investment process and therefore endow them with a higher financial risk tolerance (see Baker and Haslem, 1974; Sung and Hanna, 1996). Shaw (1996) derives a model which suggests an element of circularity in this argument however, as the relative risk aversion of an individual is shown to determine the rate of human capital acquisition. While testing the efficacy of demographics on risk tolerance, Grabble and Lytton (1998), took 2626 respondents in United States of America. They used discriminate analysis to separate, discriminate, estimate and classify investors. They concluded that whites were more tolerant than blacks. Equally, by heuristics they agree that individuals with higher levels of education are proportionately more likely to have higher risk tolerance than individuals with lower educational levels.

Schooley and Worden (1996), constituted a sample of 3143 households in America. They concluded that investors make their portfolio allocation based on their time horizon and risk tolerance. About half of them or less reported that they were not willing to take financial risks, whereas only a quarter of investors with time horizon of 10 years or more were not willing to take risk. Investors with post-secondary education held higher percentage of their assets in securities, while couples held a large percentage on equity. Using the 1989 SCF sponsored by the United States Federal Reserve Board, the researchers gathered detailed information on all assets and liabilities of 
households, as well as demographic characteristics of households to measure their attributes about the economy, financial planning and savings, as well as risk taking for investments.

Individuals with higher level of education are found to take more risk, Sung and Hanna (1996), however it could be argued that financial knowledge is more important than general education achievement influencing risk taking attitude for example an investor with a master's degree in history may be less tolerant than an individual with a diploma in financial management. Grable and Joo (2004), argue that financial education may have influence on an individual's risk tolerance /aversion determination. They recommend a further study to test the hypothesis of whether business /financial education background or specialization would significantly influence an individual's risk tolerance level.

While some researchers have found that people with higher education usually show more risk tolerance behavior compared to others, contrary findings also exist. The former researchers argue that with increase in the level of education, people become capable of assessing the risk and benefits more carefully than those who are with less education. There is evidence to suggest that higher education encourages people to take more financial risks and a person who is more educated is more risk tolerant than a person with lower level of education (Grable \& Lytton, 1999; Grable, 2000 and Al-Ajmi, 2008). In contrast Faff et al (2004) found that education was not a significant determinant of a person's risk tolerance behavior. However, these findings have created an increased interest in including „education" as a variable that explain financial risk tolerance. From the above review it is therefore necessary to test the influence of the above variables on the determination of risk tolerance. The research hypotheses were therefore formulated as follows:

$\mathrm{H}_{1}$ : Education level does not affect investor risk tolerance

$\mathrm{H}_{2}$ : Specialization in finance or accounting does not affect investor risk tolerance

\subsection{Data and methodology}

\subsection{Research design}

This study adopted a complex descriptive approach to evaluate the determinants of an individual investor's risk tolerance. Investor attributes such as bio-psychological, financial and sociocultural were hypothesized to influence an individual's inclination towards risk. Data on the said attributes which include investor's age, financial literacy, income, household status, home ownership as well as racial/ethnic orientation were obtained through a questionnaire.

\section{Target population:}

The population of investors from whom a sample for assessing individual risk tolerance in Kenya, comprised of all investors holding accounts with the Central Depository Systems Corporation (CDSC), was drawn. The total number of investors was 932,510 as at $30^{\text {th }}$ September 2010 (CMA, 2010). The CDSC was created by the Central Depository Act 2000 to establish and operate a system for a central handling of securities in Kenya, provide immobilization and eventual dematerialization of, and dealings in securities deposited there with in the country and for connected purposes; such securities are immobilized or dematerialized and dealings in respect of those securities are affected by means of entries in securities accounts without physical necessity of certificates. The CDSC provides a reliable source of demand for investments in the Kenyan capital market. The system has created a databank which is ideal for a framework for establishing whether investment managers, advisors and individuals assess their risk tolerance levels before selecting an investment portfolio given limited resources.

Sampling frame and technique:

Since the population variance with respect to the dependent variable is unknown and also because a large portion of the predictor and criterion variables are measured as categorical and not continuous variables, the sample size estimate follows the recommendations by Bartlett et al. (2001) and Sekaran (2011), in the form shown below:

$$
\mathrm{n}_{0}=\frac{(\mathrm{t})^{2} * \mathrm{p} * \mathrm{q}}{(\mathrm{d})^{2}}=\frac{(2.58)^{2} * 0.75 * 0.25 \mathrm{q}}{(.05)^{2}}=499.23=500 \text { (approx.) }
$$

Where $n_{0}$ is the sample size, " $\mathrm{t}$ " = the value for the selected alpha level of $1 \%$ in each tail to increase precision, hence 2.58; (p) (q) =estimates of variance; where "d" is the acceptable margin of error for the proportion being estimated, that is error researcher is willing to accept $=5 \%$. The selected sample size, of 500 , is further informed by three factors: the desire to reduce the sampling error, many respondents may not fill all the details and lowering the number of valid responses, and the fact that the target population is expected to be highly heterogeneous with respect to a number of the internal variables under study. A random sample of 500 individual investors was selected from 22 investment banks and 3 stock brokers which represent the entire licensed brokerage firms by the 
CMA as at 31 December 2011. A simple random sample was drawn from all the account holders in each investment bank and stock broker, which is considered manageable in terms of costs and representative of all custodians in contact with individual investors.

\subsection{Analysis tools}

Descriptive statistics cross tabulation; ordinal logistic regression and correlation analysis was employed to analyze the data. Histogram of risk tolerance and mean, median score and standard deviations forms descriptive statistics, which were further analyzed through statistical package for social sciences (SPSS 20) to determine various coefficients, standard error, regression equations tests, Wolfowitz Wald test, one way as well as paired Analyses of variance (ANOVA) was performed on the data. Ordinal logistic regression was applied to test the implication of individual variable in the determination of an individual's risk tolerance in relation to other variables that have specific ordered characteristics. The log of odds for increase or decrease was obtained for each coefficient of the variables holding others variables constant as explained in the section below. Each value of the independent components was obtained in the questionnaire and a score ranging to a scale of 47 using a 13 -item risk tolerance measurement questionnaire (Grable and Lyton, 1999).

An ordinal logistic regression analysis was preferred, since risk tolerance is deemed to be a function of these selected variables of education level and specialization of an individual; which had been categorized into ordered responses. Investor education level was classified into five main categories such as below high school, high school, college and first degree, postgraduate diploma and masters' degree as well as doctorate and above. Financial knowledge of an investor was determined by specialization in professional accountancy or finance on full or partial level. The maximum possible score was 47. A score of 33 and above categorized as very high risk tolerances, 29-32; Above average risk tolerance, 23-28 average risk tolerance ; $19-22$ below average while 0-18 low risk tolerance. The equations for this model are as follows:

$$
\begin{aligned}
& \operatorname{logit}(\mathrm{p})=\log [\mathrm{p} /(1-\mathrm{p})]=\ln [\mathrm{p} /(1-\mathrm{p})] \\
& \operatorname{Logit} \mathrm{p}=\frac{p}{1-p}=\beta \mathrm{O}+\beta \mathrm{eE}+\beta \mathrm{s} S \ldots \ldots \ldots \ldots
\end{aligned}
$$

Where $\mathrm{p}$ is the probability of risk tolerance of an investor

$$
\mathrm{p}=\frac{\mathrm{e}^{\beta \mathrm{o}+\beta \mathrm{eE}+\beta \mathrm{SS}}}{1+\mathrm{e}^{\beta \mathrm{o}+\beta \mathrm{eE}+\beta \mathrm{sS}}}
$$

Where,

$\beta_{0}=$ coefficient of the constant variable

$\beta_{\mathrm{eE}}=$ coefficient of investor level of education

$\beta_{\mathrm{e}} \mathrm{s}=$ coefficient of specialization/qualification in accounting or finance

$\varepsilon^{\prime}$ í is the error term.

P-represents the logit of risk tolerance; it's the log of odds in which risk tolerance occurs. The risk tolerance score was ordered in to 5 levels; very high score 33 and above, above average 29-32, average score 23-28, below average 19-22 and very low 0-18.

\subsection{Results and discussion}

\subsection{Education and risk tolerance scores}

Very high score of risk tolerance was not reported among those with less than high school education; 22 investors with between high school and college had very high risk tolerance, 12 with first degrees; 40 with post graduate diploma and masters; 3 doctorate and above level of education out of a total of 137 respondents. Above average score had a total of 161 including 27 high schools to college, 77 first degrees; 54 post graduate and masters' level and 3 with doctorate and above. Those with below average risk tolerance were 2 college, 13 first degree, 9 post graduate diploma average risk tolerance was reported with 4 less than high school, 36 high school college , 81 first degree 42 post graduate diploma-master and 4 doctorate and above. There were 2 people with low risk tolerance at high school college levels, postgraduate diploma and first degree. Table 01 presents the cross tabulation results.

Table 01: RTS * Education level Cross tabulation

\begin{tabular}{lcccccc} 
& \multicolumn{4}{c}{} & \multicolumn{2}{c}{ Education level } \\
\cline { 2 - 5 } & $\begin{array}{c}\text { Less than high } \\
\text { school }\end{array}$ & $\begin{array}{c}\text { High school - } \\
\text { college }\end{array}$ & $\begin{array}{c}\text { First } \\
\text { degree }\end{array}$ & $\begin{array}{c}\text { Postgraduate diploma- } \\
\text { Master degree }\end{array}$ & $\begin{array}{c}\text { Doctorate } \\
\text { and above }\end{array}$ & $\begin{array}{c}\text { Total } \\
\text { Risk Tolerance Scores } \\
\text { Very high }\end{array}$ \\
0 & 22 & 72 & 40 & 3 & 137 \\
\end{tabular}




\begin{tabular}{|c|c|c|c|c|c|c|}
\hline Above average & 0 & 27 & 77 & 54 & 3 & 161 \\
\hline Average & 4 & 36 & 81 & 42 & 4 & 167 \\
\hline Below average & 2 & 4 & 13 & 9 & 0 & 28 \\
\hline Low risk tolerance & 0 & 2 & 2 & 2 & 1 & 7 \\
\hline Total & 6 & 91 & 245 & 147 & 11 & 500 \\
\hline
\end{tabular}

Exact chi square test on correlation was observed to have a P value of 0.078 , and therefore at $\alpha=7.8 \%$ Education levels would singly contribute to risk tolerance; Likelihood ratio had a P value of 0.164 . All levels of education beginning from less than high school to doctorate level of education had average score of risk tolerance, except those with post graduate diploma and masters' degree, who had scored above average risk tolerance. This result could have been expected for those with doctorate degree except that the numbers of the doctorate degree holders in the sample were fewer relative to the others in the category. It may therefore be concluded that risk tolerance generally increases with the level of education, since education provides new experiences and exposure to individuals. The figure below shows details of the levels of risk tolerance for each of the categories of investor education.

Any qualification in accounting or finance:

Of those who had full or partial qualification in accounting or finance 83 had very high risk tolerance scores 100 below average, 82 average, 14 below average and 1 low risk while; among those without qualification, 55 had very high risk tolerance, 63 above average, 85 average, 15 below and 6 low risk tolerance. Those with qualification or specialization in finance or accounting had above average risk tolerance while those without specialization scored average risk tolerance. Those who were specialized would be willing to take more risk other things being equal; this could be due to the understanding of the finance discipline or financial literacy of the expectations of financial instruments. This variable was quite significant on its own in the determination of risk tolerance level of the investors. The Pearson chi had a P value of 0.020 while the likelihood ratio recorded a P value of 0.017 . Table 02 presents cross tabulation results between risk tolerance and specialization in accounting or finance.

\begin{tabular}{lccr}
\hline \multicolumn{2}{c}{ Table 02: Any qualification in accounting/finance and risk tolerance } & \multicolumn{2}{c}{ Total } \\
\cline { 2 - 3 } Risk tolerance & accounting/finance & \\
\cline { 2 - 4 } Very high & 83 & 55 & 138 \\
Above average & 100 & 63 & 163 \\
Average & 82 & 85 & 167 \\
Below average & 14 & 15 & 29 \\
Low risk tolerance & 1 & 6 & 7 \\
\hline Total & 280 & 224 & 504 \\
\hline
\end{tabular}

One way analysis of variance was performed for the two variables on risk tolerance. It was established that the level of education and specialization contributed highly to the risk tolerance of each of the individuals interviewed. Education recorded a significance with a P value of 0.049 as seen in table 02 , which is below $\alpha=5 \%$ at $95 \%$ confidence interval while specialization or qualification showed a significance with a P value of 0.005 as shown in table 03 below. Specialization contributed heavily in determining the risk tolerance level of investors because of financial knowledge exposure among these individuals. Financial literacy is thus more important than general education; however education per se would still influence an individual's risk tolerance level.

\begin{tabular}{llllll}
\hline \multicolumn{5}{c}{ Table 03: RTS and Specialization ANOVA } \\
\hline & Sum of Squares & Df & Mean Square & F & Sig. \\
\hline Between Groups & 7.232 & 1 & 7.232 & 8.003 & .005 \\
Within Groups & 453.625 & 502 & .904 & & \\
Total & 460.857 & 503 & & & \\
\hline
\end{tabular}

\begin{tabular}{llllll}
\hline \multicolumn{5}{c}{ Table 04: RTS and education ANOVA } \\
\hline & Sum of Squares & Df & Mean Square & F & Sig. \\
\hline Between Groups & 202.535 & 4 & 50.634 & 2.401 & .049 \\
Within Groups & 10439.857 & 495 & 21.091 & & \\
Total & 10642.392 & 499 & & & \\
\hline
\end{tabular}




\subsection{Ordinal logistic regression model (OLRM)}

SPPS ordinal procedure (Polytomous Universal Model -PLUM) was used to analyze the data to preserve the natural ordering of data. This is an extension of general regression model to logistic ordinal of general categories. Table 04 provides the summary statistics of the model. It's a combination of parameter into probabilities of the dependent variable occurring. The risk tolerance score was ordered in to 5 levels; very high score 33 and above, above average 29-32, average score 23-28, below average 19-22 and very low $0-18$. The model fitted at $\mathrm{P}=0.006$ which is less than $\mathrm{P}=0.050$, as shown on the table 05 below.

\begin{tabular}{lllll}
\hline \multicolumn{3}{c}{ Table 05: model fitting } \\
\hline Model & -2 Log Likelihood & Chi-Square & df & Sig. \\
Intercept Only & 149.204 & & & \\
Final & 133.049 & 16.155 & 5 & .006 \\
\hline Link function: Logit. & & & & \\
\hline
\end{tabular}

The parameter estimates indicated in table 07 below, were computed with SPSS calculating standard error and a Wald test which is a variant of $\mathrm{z}$ test was performed through the program. Education below high school level was found to be considerably significant in determination of risk tolerance with $\mathrm{P}=0.053$ almost equivalent to $\alpha=5 \%$. Those with less than high school education are therefore influential to risk tolerance. For each unit increase in education level from below high school level, the expected ordered log of odds of risk tolerance increased by 1.831 , for each unit increase in education level between high school and college the expected log of odds of risk tolerance reduced by 0.102 while for each unit increase in education level from first degree the expected log of odds of risk tolerance reduced by 0.261 and for each unit increase of education level from masters the expected log of odds of risk tolerance reduced by 0.353 as the threshold for risk tolerance rises holding other factors constant.

The risk tolerance scores increases with the level of education, below high school level respondents had an average RTS less than 25. The scores increased to 30 from high school level to doctorate level of education as shown in the appendix. The study reveals that level of education influences an individual's willingness to take investment risk and that higher levels of attained education are associated with increased levels of risk tolerance, because education plays an important role in the level of understanding of risks inherent to the financial investment and therefore higher education encourages taking more financial risk. Therefore this research concurs with Grable and Lytton (1998). Grable and Lytton (1999), Grable (2000), Grable and Joo (2004) and Al-Ajmi (2008) who found that individuals with higher attained education were more risk tolerant than individuals with lower attained educational levels, although it contradicts Faff et al. (2004) found that education was not a significant determinant of an individual's attitude towards risk.

\begin{tabular}{llrr}
\hline & & & \\
\hline & Table 06 : Logistic regression & case processing summary & Marginal Percentage \\
& Above average & 136 & $27.3 \%$ \\
RTS & Average & 161 & $32.3 \%$ \\
& Below average & 167 & $33.5 \%$ \\
& Low risk tolerance & 28 & $5.6 \%$ \\
& Less than high school & 7 & $1.4 \%$ \\
\hline & High school - college & 6 & $1.2 \%$ \\
Education level & First degree & 91 & $18.2 \%$ \\
& Postgraduate diploma- Master & 244 & $48.9 \%$ \\
& degree & 147 & $29.5 \%$ \\
Any qualification in & Doctorate and above & 11 & $2.2 \%$ \\
accounting/finance & Yes & 277 & $55.5 \%$ \\
Valid & No & 222 & $44.5 \%$ \\
Missing & & 499 & $100.0 \%$ \\
\hline Total & & 7 & \\
\hline
\end{tabular}

Qualification or specialization in finance or accounting was found to be significant in determination of risk tolerance at $\mathrm{P}=0.022$ which is Greater than 0.050 therefore the null hypothesis that specialization does not influence an investor's risk tolerance was rejected. For every single unit increase in specialization or qualification in accounting or finance, the expected ordered log of odds of risk tolerance reduced by 0.389 as the threshold of risk tolerance rises holding other variables constant. 
Figure 01: Education and risk tolerance

EDUCATION AND RTS

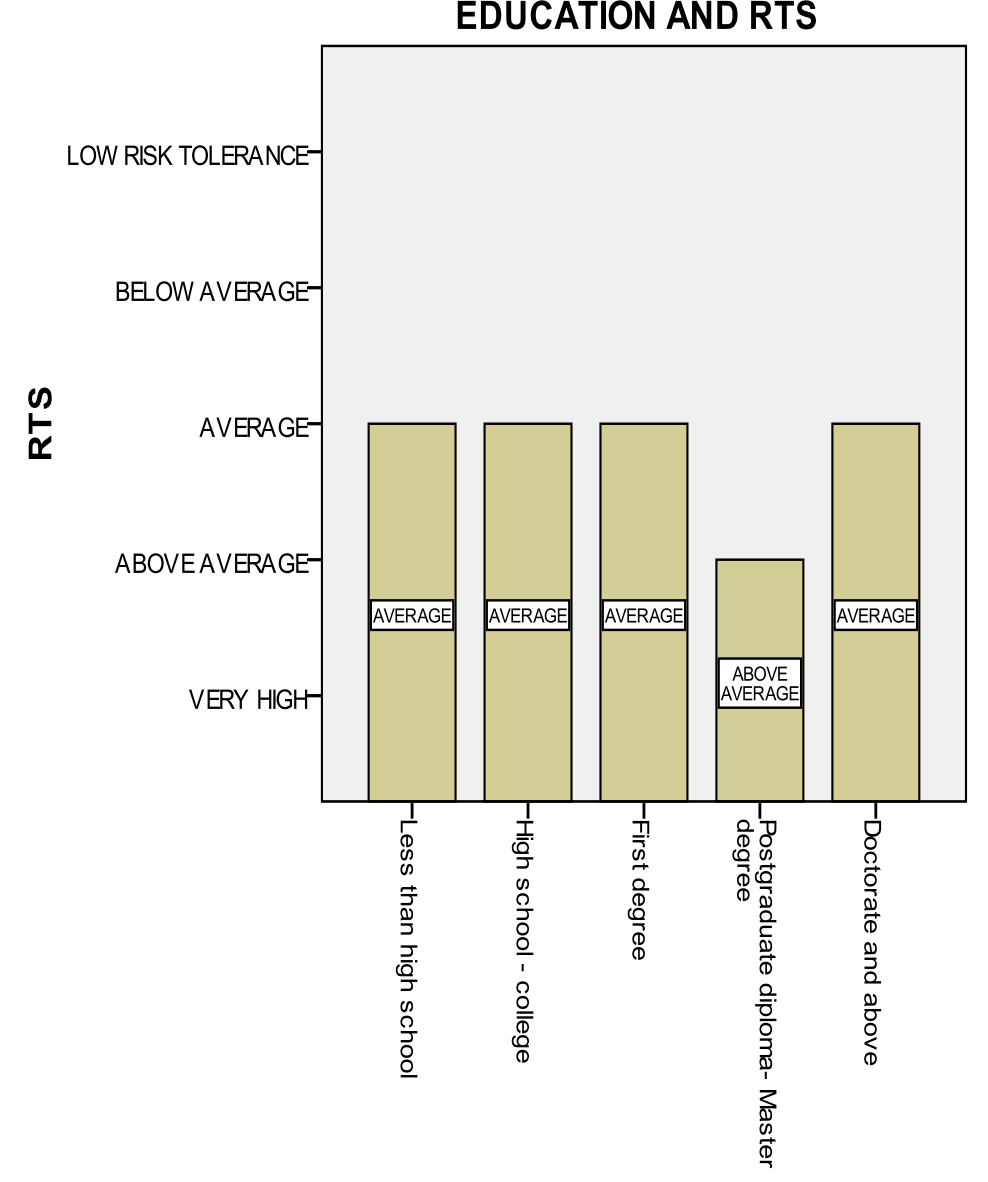

Figure 02: Specialization and risk tolerance

SPECIALIZATION AND RTS

Bars show Mode

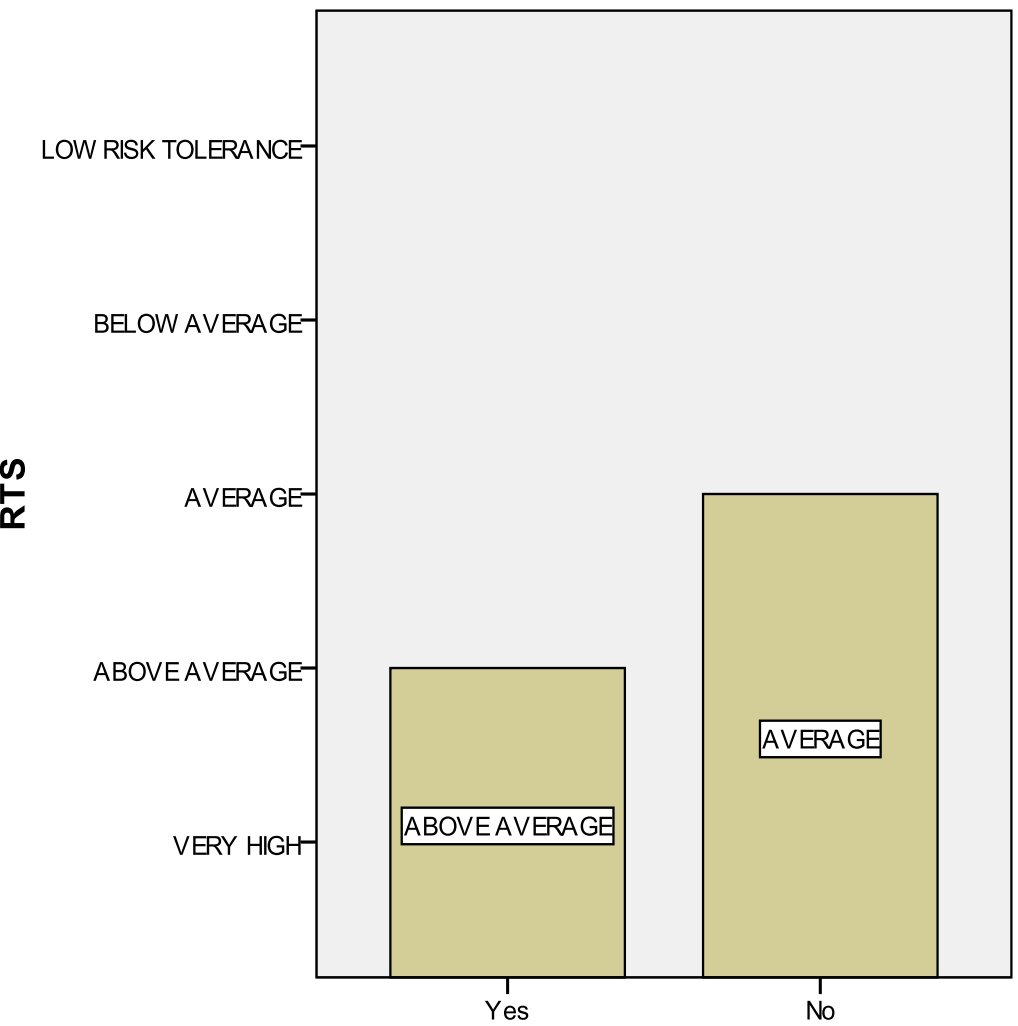

Any qualification in accounting/finance 
This implied that those who had partial or full qualification in accounting and or finance had higher average score of risk tolerance compared to those without qualification or specializations as indicated in the appendix. Grable and Joo (2004) argued that financial education may have influence on an individual's risk tolerance determination. They recommend a further study to test the hypothesis of whether business /financial education background or specialization would significantly influence an individual's risk tolerance level.

\begin{tabular}{|c|c|c|c|c|c|c|}
\hline & & Estimate & Std. Error & Wald & $\begin{array}{l}\text { Deg of } \\
\text { freedom }\end{array}$ & Sig. \\
\hline \multirow{4}{*}{ Threshold } & {$[\mathrm{RTS}=1]$} & -1.454 & .568 & 6.542 & 1 & .011 \\
\hline & {$[\mathrm{RTS}=2]$} & -.059 & .564 & .011 & 1 & .916 \\
\hline & {$[\mathrm{RTS}=3]$} & 2.208 & .583 & 14.352 & 1 & .000 \\
\hline & {$[\mathrm{RTS}=4]$} & 3.897 & .675 & 33.316 & 1 & .000 \\
\hline \multirow{7}{*}{ Location } & [Var1_Quez6_Education_level=1] & 1.831 & .948 & 3.730 & 1 & .053 \\
\hline & [Var1_Quez6_Education_level=2] & -.102 & .584 & .030 & 1 & .862 \\
\hline & [Var1_Quez6_Education_level=3] & -.261 & .562 & .215 & 1 & .643 \\
\hline & [Var1_Quez6_Education_level=4] & -.353 & .572 & .382 & 1 & .537 \\
\hline & [Var1_Quez6_Education_level=5] & $0^{\mathrm{a}}$ & & . & 0 & . \\
\hline & $\begin{array}{l}\text { [Var1_Quez7_AnyQualification_ac } \\
\text { counting_finance=1] }\end{array}$ & -.389 & .170 & 5.257 & 1 & .022 \\
\hline & $\begin{array}{l}\text { [Var1_Quez7_AnyQualification_ac } \\
\text { counting_finance=2] }\end{array}$ & $0^{\mathrm{a}}$ & & & 0 & \\
\hline
\end{tabular}

\subsection{Conclusion and policy implication}

Investors with higher levels of education were more risk tolerant than those with lower level of education, thus risk tolerance was positively related to education level, however the education level was more significant at below high school level compare to other levels therefore it is necessary for stock market investors to complete high school. The significance level increased as the level of education increased to doctorate level this may be associated to the level of reasoning before accepting to tolerate risk. Those with accounting and/or finance qualification were more risk tolerant than non-specialist in these thematic areas therefore the inclination towards risk is influenced by specialization.

Capital Market Authority should design more elaborate investor education plans that can reduce the significant challenge of very low risk tolerance as exposed in the research for those investors with less than high school education. As the Nairobi Securities Exchange (NSE) becomes more vibrant, it would also be appropriate for part of school curriculum at primary level of education to highlight on securities offered at the securities exchange and the role of the market in the economy as indicated in Kenya vision 2030 economic pillar. Investor education can also be promoted at the country level with appropriate county budget to enable many Kenyans understand their risk tolerance level.

Although specialization or lack of specialization is an individual's volition, the government as well as fund managers should make conscious efforts to provide basic understanding of the available security instruments at the securities market to enable investors select portfolio of assets that are equivalent to their risk profiles. The NSE and CMA should develop a standard investment profiling questionnaire that incorporates basic attributes such as financial education and financial knowledge to guide Kenyan investors.

\section{References}

Al-Ajmi, J.Y., 2008. Risk tolerance of individual investors in an emerging market. International Research Journal of Finance and Economics, 17: 15-26.

Arrow, J. \& Pratt J.W. 1965. Risk aversion in the small and in the large Econometrica, 32: 122-136.

Baker, H. K., \& Haslem, J. A., 1974. The impact of investor socioeconomic characteristics on risk and return preferences. Journal of Business Research, 2(4): 469-476. http://dx.doi.org/10.1016/0148-2963(74)90032-0

Barsky, R. B., Kimball, M. S., Juster, F. T., \& Shapiro, M. D., 1997. Preference parameters and behavioral heterogeneity: an experimental approach in the health and retirement survey (No. w5213). National Bureau of Economic Research.

Bartlett, J. E. II., JW Kotrlik, \& CC Higgins, 2001. Organizational Research: Determining Appropriate Sample Size in Survey Research. Information Technology, Learning, and Performance Journal, 19(1). 
Brennan, M. J., \& Kraus, A., 1976. The geometry of separation and myopia. Journal of Financial and Quantitative Analysis, 11(02): 171-193. http://dx.doi.org/10.2307/2979048

CMA (2010) Quarterly Statistical Bulletin, Quarter Ended September 2010.Issue 5/2010 Capital Markets Authority 2010

Hallahan, T. A., Faff, R. W., \& McKenzie, M. D., 2004. An empirical investigation of personal financial risk tolerance. Financial Services Review, 13(1): 57-78.

Faff, R., Mulino, D., \& Chai, D., 2008. On the linkage between financial risk tolerance and risk aversion. Journal of Financial Research, 31(1); 1-23. http://dx.doi.org/10.1111/j.1475-6803.2008.00229.x

Friedman, M., \& Savage, L. J., 1948. The utility analysis of choices involving risk. The Journal of Political Economy, 279-304. http://dx.doi.org/10.1086/256692

Friend, I., \& Blume, M.E., 1975. The demand for risky assets. American Economic Review, 75: 900 -922.

Grable, J. E., \& Lytton, R. H., 1994. Assessing financial risk tolerance: Do demographic, socioeconomic, and attitudinal factors work. Family Relations and Human Development/Family Economics and Resource Management Biennial, 3: 80-88. http://dx.doi.org/10.1023/A:1022994314982

Grable, J. E., 2000. Financial risk tolerance and additional factors that affect risk taking in everyday money matters. Journal of Business and Psychology, 14(4): 625-630.

Grable, J. E., \& Joo, S., 1997. Determinants of risk preference: Implications for family and consumer science professionals. Family Economics and Resource Management Biennial, 2: 19-24.

Grable, J. E. and Lytton, 1998. Investor's risk tolerance: testing the efficacy of demographics as differentiating and classifying factors. Association for Financial Counseling and Planning, 9(1): 61-74.

Grable, J. E., \& Joo, S. H., 1999. Factors related to risk tolerance: A further examination. Consumer Interests Annual, 45: 53-58.

Grable, J. E., \& Joo, S. H., 2004. Environmental and Biophysical Factors Associated with Financial Risk Tolerance. Journal of Financial Counseling and Planning, 15(1):73-82.

Grable, J., Lytton, R. H., O'neill, B., Joo, S. H., \& Klock, D., 2006. Risk Tolerance, Projection Bias, Vividness, and Equity Prices. The journal of investing, 15(2): 68-74. http://dx.doi.org/10.3905/joi.2006.635632

Hanna, S. D., \& Lindamood, S., 2005. Risk tolerance of married couples. Proceeding of the Academy of Financial Services, 13 (4).

Hanna, S., \& Chen, P., 1997. Subjective and objective risk tolerance: Implications for optimal portfolios. Financial Counseling and Planning, 8(2): 17-26.

Irwin, C.E, 1993. Adolescence and Risk Taking: How are they Related? In J. Bell \& R.W Bell (eds) Adolescent risk taking Newsbury, park C.A: Sage

Jackson, D. N., Hourany, L., \& Vidmar, N. J., 1972. A four-dimensional interpretation of risk taking1. Journal of Personality, 40(3): 483-501. http://dx.doi.org/10.1111/j.1467-6494.1972.tb00075.x

Nofsinger, J., \& Baker, 2002. Investment, Prentice Hall, New Jersey.

Paun, C Radu , M, Lulian, B., 2007. Empirical evidence of risk aversion for individual Romanian capital market investors. MPRA, 6842, 22

Roszkowski, M.J., 1999. Risk tolerance and risk aversion. Financial Planning, 213-225.

Roszkowski, M.J., 1993. Risk-tolerance in financial decisions. In R.M. Crowe Hughes (Eds).Fundamentals of Financial Planning (2 ${ }^{\text {nd }}$ Ed.) Bryn Mawr. PA The American College.

Roszkowski, M., \& Grable, J., 2005. Estimating risk tolerance: The degree of accuracy and the paramorphic representations of the estimate. Journal of Financial Counseling and Planning, 16(2).

Sekaran,U.,(2011) Research methods: A skill building approach. $4^{\text {th }}$ Edition John Wiley \& Sons

Schooley, D. K., \& Worden, D. D., 1996. Risk aversion measures: Comparing attitudes and asset allocation. Financial services review, 5(2): 87-99. http://dx.doi.org/10.1016/S1057-0810(96)90003-7

Shaw, K. L., 1996. An empirical analysis of risk aversion and income growth. Journal of Labor Economics, 626-653. http://dx.doi.org/10.1086/209825

Shefrin, H., 2001. Behavioral corporate finance. Journal of Applied Corporate Finance, 14(3):113-126. http://dx.doi.org/10.1111/j.1745-6622.2001.tb00443.x

Sulloway, F.J, 1997. Born to rebel: Birth order, family dynamics and creative lives. Boston Pantheon.

Sung, J., \& Hanna, S., 1996. Factors related to risk tolerance. Financial Counseling and Planning, 7, 11-20.

Wang, C., \& Hanna, S. D., 2007. Racial/ethnic disparities in stock ownership: A decomposition analysis. Consumer Interests Annual, 53.

Wang, C., \& Hanna, S. D., 2007. The risk tolerance and stock ownership of business owning households. Financial Counseling and Planning, 18(2): 3-18.

Xiao, J. J., Alhabeeb, M. J., HONG, G. S., \& Haynes, G. W., 2001. Attitude toward Risk and Risk-Taking Behavior of Business-Owning Families. Journal of Consumer Affairs, 35(2): 307-325. http://dx.doi.org/10.1111/j.17456606.2001.tb00116.x

Yuen, W.,T \& Chen.,C.W., 2008. Investor risk tolerance: A survey of Hong Kong. Working Paper Series. Economics Department Hong Kong University. 